\title{
Turbulence Descriptions in Two Cobble-Bed River Reaches
}

\author{
Mark C. Stone, M.ASCE${ }^{1}$; and Rollin H. Hotchkiss, P.E., M.ASCE ${ }^{2}$
}

\begin{abstract}
The hydrodynamic flow field in streams and rivers influences many ecological processes including organism dispersal, habitat use, and resource acquisition. Understanding the linkages between hydrodynamic and ecological processes is essential for developing effective restoration and management tools. Despite the pervasive influence of flow velocity and turbulence, the details of natural stream flow fields as they apply to ecological concepts are poorly understood. In this study, velocity and turbulence distributions were investigated at two spatial scales using an acoustic Doppler velocimeter. The measurements were collected in two cobble-bed rivers with mean depths of approximately $0.5 \mathrm{~m}$, relative roughness values between 0.12 and 0.33 , and streamflow rates of 1.5 and $3.1 \mathrm{~m}^{3} / \mathrm{s}$. The analysis included mean velocity, Reynolds shear stress $\left(\tau_{R}\right)$, turbulence intensity $(\mathrm{TI})$, and turbulent kinetic energy (TKE) vertical profiles and horizontal heterogeneity collected in riffle, run, and pool habitat units. The measured profiles were compared with previously reported semiempirical equations. The logarithmic profile reasonably described the vertical velocity profiles. However, the observed TI, TKE, and $\tau_{R}$ profiles deviated noticeably from the semiempirical relationships. Velocity magnitude and cross-correlation coefficients revealed strong spatial heterogeneity at both the reach and fine scales. Spatial heterogeneity was also observed in TI and TKE data, but to a lesser degree. The results provide a novel description of flow field characteristics in cobble-bed rivers while demonstrating techniques for measuring velocity and turbulence distributions in natural streams in the context of an ecohydraulics study.
\end{abstract}

DOI: $10.1061 /(\mathrm{ASCE}) 0733-9429(2007) 133: 12(1367)$

CE Database subject headings: Turbulence; Acoustic techniques; Measurement; Ecology; Open channels; Rivers; Velocity.

\section{Introduction}

The hydrodynamic flow field influences many ecological processes in aquatic environments. For example, organism dispersal, habitat use, resource acquisition, and competitor/prey relationships are all affected by the flow parameters (Hart and Finelli 1999). Restoration and management of stream ecosystems require conceptual and numerical models capable of describing the linkages between hydrodynamic and ecological processes. However due to the complex nature of natural stream flow fields and the processes that depend upon them, descriptions of such linkages remain primarily qualitative in nature. This paper strengthens linkages by demonstrating techniques for conducting advanced hydrodynamic measurements in natural streams at multiple spatial scales in the context of an ecosystem study.

Periphyton (algae and associated bacteria and fungi on aquatic substrates) provides a major source of primary production for many aquatic ecosystems (Wetzel 2001). In excess, periphyton becomes a nuisance, causing large diel fluctuations in dissolved oxygen; which may lead to fish kills and other undesirable conditions. The periphyton mat can be seen as an adaptive system

\footnotetext{
${ }^{1}$ Assistant Research Professor, Division of Hydrologic Sciences, Desert Research Institute, Las Vegas, NV 89119 (corresponding author). E-mail: mark.stone@dri.edu

${ }^{2}$ Associate Professor, Dept. of Civil and Environmental Engineering, Brigham Young Univ., Provo, UT 84602. E-mail: rhh@byu.edu

Note. Discussion open until May 1, 2008. Separate discussions must be submitted for individual papers. To extend the closing date by one month, a written request must be filed with the ASCE Managing Editor. The manuscript for this paper was submitted for review and possible publication on April 5, 2006; approved on June 21, 2007. This paper is part of the Journal of Hydraulic Engineering, Vol. 133, No. 12, December 1, 2007. CASCE, ISSN 0733-9429/2007/12-1367-1378/ $\$ 25.00$.
}

responding to prevailing environmental conditions. Periphyton production responds to numerous environmental factors including light, substrate, nutrient concentrations, insect grazing, and flow regime. Inaccuracies associated with the prediction of periphyton biomass in streams result largely from a failure to incorporate the influence of hydrodynamics into environmental models. The hydrodynamic flow environment affects two counteracting processes that influence periphyton biomass accrual: nutrient mass transfer into the mat and removal by sloughing due to shear stress and drag. In turn, these processes influence periphyton assemblage architecture and biomass, metabolism, photosynthesis, and oxygen dynamics. Investigations of these complex processes require detailed information about the flow field, particularly near the streambed, including descriptions of velocity profiles, shear stress distributions, and turbulence. Our desire to improve understanding about the linkages between periphyton assemblages and the hydrodynamic flow field of natural rivers was the motivation behind this research.

The objective of this research was to demonstrate how turbulent flow field data contribute to an ecohydraulics study. This was accomplished by conducting acoustic Doppler velocimeter (ADV) measurements in two cobble-bed rivers at two spatial scales. The results advanced understanding of the spatial heterogeneity of hydrodynamic properties in natural rivers.

\section{Background}

\section{Hydrodynamic Descriptions}

The description of flow velocity can be separated into mean velocity and turbulent fluctuations. Mean velocity is typically timeaveraged at a point in the flow field. This definition can be expanded to a depth-integrated mean and often as a cross- 
sectional mean. Ecological investigations of hydrodynamic processes almost exclusively rely on spatially and time-averaged mean velocity. This is particularly true for in situ observations. However, most ecological processes are influenced by both mean and turbulent flow features which are typically heterogeneous in natural environments. Such limitations in ecological investigations are the result of the complexities of natural flow fields and in the challenges involved in measuring three-dimensional velocity and turbulence parameters.

The separation of velocity into mean and turbulent components is formalized through the Reynolds decomposition (Reynolds 1974)

$$
u^{\prime}=u-\bar{u}
$$

where $u^{\prime}, u$, and $\bar{u}=$ fluctuating, instantaneous, and time-averaged velocities, respectively. The spatial and temporal distributions of these velocity components are described using numerous hydrodynamic variables as discussed by Nezu and Nakagawa (1993).

The distribution of mean and turbulent flow parameters in open channels has been the topic of numerous investigations. Most of these studies have been conducted in laboratory flumes and have resulted in several predictive semiempirical equations. The "law of the wall" or "log-law," developed by Prandtl (1932) and von Kármán (1930) for smooth boundaries, was modified by Nikuradse (1933) and others to the following log-law for hydraulically rough boundaries

$$
\frac{\bar{u}}{u^{*}}=\frac{1}{\kappa} \ln \left(\frac{z+\Delta z}{k_{s}}\right)+B
$$

where $\bar{u}=$ local time-averaged velocity; $u^{*}=$ friction velocity; $\kappa=$ von Kármán constant; $z=$ distance from the bed; $\Delta z=$ displacement length; $k_{s}=$ roughness height; and $B=$ integration constant. In this paper $Z=z+\Delta z$, where $Z=$ distance above the point where the velocity profile equals zero.

The friction velocity is directly related to the bed-shear stress as

$$
u_{*}=\sqrt{\tau_{0} / \rho}
$$

where $\tau_{0}=$ bed-shear stress; and $\rho=$ fluid density. $u_{*}$ is often the desired result of Eq. (2) where it is determined from measured velocity data using a regression technique. It also can be calculated at the reach scale, referred to as global in this paper, from the bed-shear stress as determined from the water surface slope as

$$
\tau_{g}=\gamma R_{H} S
$$

where $\gamma=$ fluid specific weight; $R_{H}=$ stream hydraulic radius; and $S=$ water surface slope. The shear stress can also be calculated from the Reynolds shear stress distribution, $\tau_{R}$. The total shear stress is the result of viscous and Reynolds stresses, which for two-dimensional flow can be represented as

$$
\tau=\mu \frac{d \bar{u}}{d z}-\rho \overline{u^{\prime} w^{\prime}}
$$

where $\mu=$ dynamic viscosity; $d \bar{u} / d z=$ vertical velocity gradient; $\rho=$ fluid density; and $\overline{u^{\prime} w^{\prime}}=$ time-averaged cross correlation coefficient between the streamwise $(u)$ and vertical $(w)$ velocity components. $\tau_{R}$ is represented by the term $-\rho \overline{u^{\prime} w^{\prime}}$. For natural streams, $\tau_{\mathrm{R}}$ dominates and the viscous term can be neglected. By integrating the Navier-Stokes equations for the water depth, $h$, a theoretical $\tau_{\mathrm{R}}$ distribution can be derived for two-dimensional flow as (Nezu and Nakagawa 1993)

$$
\frac{-\overline{u^{\prime} w^{\prime}}}{u_{*}^{2}}=1-\frac{Z}{h}
$$

Researchers have also suggested universal functions for turbulence intensity (TI) and turbulent kinetic energy (TKE). Using the $k-\epsilon$ turbulence model, equations to describe the TI and TKE distributions can be developed as follows

$$
\begin{gathered}
\mathrm{TI}_{U}=a u_{*} \exp \left(-C_{k} Z / h\right) \\
\mathrm{TI}_{V}=b u_{*} \exp \left(-C_{k} Z / h\right) \\
\mathrm{TI}_{W}=c u_{*} \exp \left(-C_{k} Z / h\right) \\
\mathrm{TKE}=d u_{*}^{2} \exp \left(-2 C_{k} Z / h\right)
\end{gathered}
$$

where $\mathrm{TI}_{U}, \mathrm{TI}_{V}$, and $\mathrm{TI}_{W}=$ streamwise, transverse, and vertical turbulence intensities at an elevation above the origin of the velocity profile $Z$, at a station with a total depth of $h ; a, b, c, d$, and $C_{k}=$ empirical constants; and $C_{k}=$ approximately equal to unity in the log-law region.

Nezu and Nakagawa (1993) suggested the following values for the empirical constants of Eqs. $(7 a)-(7 d)$ for a smooth bed: $a=2.30, b=1.27, c=1.63$, and $d=4.78$. Kironoto and Graf (1994) and Song et al. (1994) both found that Eq. (7a) described turbulence intensity profiles when $a=2.04$ for gravel bed channels (reflecting moderate relative roughness). Several researchers have shown a reduction in TI and TKE, and in particular peak values, as the relative roughness increases (e.g., Wang et al. 1993). Also the distance of the peak value from the bed increases with relative roughness (Wang et al. 1993; Carollo et al. 2005). Nezu and Nakagawa (1993) attributed this observation to the presence of bed roughness elements penetrating the flow-forcing the decomposition of large-scale vortices into smaller vortices. The local flow characteristics are strongly influenced by the form, dimension, position, and concentration of local bed elements. Given the existence of large bed particles, a localized boundary layer and a system of vortices is produced for each element (Carollo et al. 2005). Kironoto and Graf (1994) found that TI decreased for the whole flow field with increased relative roughness under a large-scale roughness condition. Carollo et al. (2005) also found that the empirical $a$ could be described as a function of relative roughness.

\section{Natural Stream Turbulence Observations}

Recently, advances in instrumentation have allowed researchers to observe turbulence features in natural rivers (Nezu 2005). Nikora and Smart (1997) completed turbulence characterizations of three New Zealand gravel-bed rivers with fast response electronic pitot tubes. Although only streamwise velocity components could be measured, the authors completed a thorough evaluation of velocity distributions and structure functions. Sukhodolov et al. (1998) completed a detailed investigation of turbulence structure around sand dunes in a straight low-land river using an ADV and a micropropeller system. The researchers found that semiempirical expressions for flow field properties were only valid for the central region of the channel. Further, they reported a clear difference in the empirical parameters for the observed data from those reported by Nezu and Nakagawa (1993). Rennie et al. (1999) conducted ADV measurements in a reach of the Salmon River in British Columbia, Canada. The measurements provided information about the spatial variability of turbulence parameters. However, measurements were only conducted at $20 \%$ of the flow 
Table 1. Hydraulic and Geometry Characteristics of Sampled Cross Sections

\begin{tabular}{|c|c|c|c|c|c|c|c|}
\hline \multirow[b]{2}{*}{ Cross section } & \multicolumn{4}{|c|}{ St. Maries reach } & \multicolumn{3}{|c|}{ Potlatch reach } \\
\hline & 1 & 2 & 3 & 4 & 1 & 2 & 3 \\
\hline Discharge, $Q\left(\mathrm{~m}^{3} / \mathrm{s}\right)$ & 3.1 & 3.1 & 3.1 & 3.1 & 1.5 & 1.5 & 1.5 \\
\hline Mean velocity $U(\mathrm{~cm} / \mathrm{s})$ & 32.1 & 42.8 & 71.9 & 20.8 & 41.7 & 32.6 & 17.8 \\
\hline Mean depth, $H(\mathrm{~m})$ & 0.49 & 0.41 & 0.39 & 0.70 & 0.35 & 0.40 & 0.73 \\
\hline Hydr. rad. $R_{H}(\mathrm{~m})$ & 0.44 & 0.38 & 0.36 & 0.67 & 0.32 & 0.36 & 0.68 \\
\hline Top width, $T_{W}(\mathrm{~m})$ & 15.6 & 16.4 & 15.6 & 16.9 & 10.9 & 11.3 & 11.1 \\
\hline Aspect ratio, $T_{W} / \mathrm{H}$ & 31.6 & 39.6 & 40.0 & 24.0 & 31.5 & 28.0 & 15.2 \\
\hline Froude number, F & 0.15 & 0.22 & 0.38 & 0.08 & 0.24 & 0.17 & 0.07 \\
\hline Reynolds number, $\mathrm{R}$ & $1.41 \mathrm{E}+05$ & $1.63 \mathrm{E}+05$ & $2.59 \mathrm{E}+05$ & $1.39 \mathrm{E}+05$ & $1.33 \mathrm{E}+05$ & $1.17 \mathrm{E}+05$ & $1.21 \mathrm{E}+05$ \\
\hline Bed slope, $S_{b}$ & 0.0018 & 0.0018 & 0.0018 & 0.0018 & 0.00038 & 0.00038 & 0.00038 \\
\hline Water slope, $S$ & 0.0012 & 0.0012 & 0.0012 & 0.0012 & 0.00024 & 0.00024 & 0.00024 \\
\hline Global friction velocity, $u_{g}^{*}(\mathrm{~m} / \mathrm{s})$ & 0.074 & 0.074 & 0.074 & 0.074 & 0.033 & 0.033 & 0.033 \\
\hline Global shear stress, $\tau_{g}\left(\mathrm{~N} / \mathrm{m}^{2}\right)$ & 5.4 & 5.4 & 5.4 & 5.4 & 1.1 & 1.1 & 1.1 \\
\hline$d_{50}(\mathrm{~cm})$ & 10.9 & 10.6 & 11.8 & 8.5 & 11.4 & 11.0 & 9.9 \\
\hline Relative roughness, $d_{50} / H$ & 0.22 & 0.26 & 0.30 & 0.12 & 0.33 & 0.27 & 0.14 \\
\hline Critical shear, $\tau_{c}\left(\mathrm{~N} / \mathrm{m}^{2}\right)$ & 88 & 86 & 95 & 69 & 92 & 89 & 80 \\
\hline
\end{tabular}

depth, preventing a thorough investigation of the flow field distributions or comparison with semiempirical equations. BuffinBelanger et al. (2000) used an array of electromagnetic current meters to confirm the existence of large-scale flow structures in the Eaton North River, Quebec. They reported a complex organization of large-scale coherent structures with no preferred sequence of events. Tritico and Hotchkiss (2005) completed turbulence observations behind boulders in two cobble-bed rivers in northern Idaho. The researchers found elevated TI and TKE and reduced integral time scales in the wake of the obstructions. The turbulence parameters did not appear to be a function of obstruction shape. Papanicolaou and Hilldale (2002) found that TI, TKE, and $\tau_{R}$ profiles were strongly influenced by channel transitions using ADV measurements in a small, low-gradient stream. Nikora and Goring (2000) reported turbulence data that closely resembled the semiempirical relationships in an irrigation channel with a fixed and weakly mobile gravel bed.

\section{Influence of Hydrodynamics on Periphyton}

The periphyton mat can be seen as an adaptive system responding to prevailing environmental conditions. Hydrodynamic properties affect two counteracting processes that influence periphyton biomass accrual: nutrient mass transfer into the mat and removal by sloughing due to shear stress and drag. With increasing velocities, nutrient mass transfer is enhanced due to an increase in the turbulent flux to the bed and through the mats, and also a progressive reduction in the thickness of the boundary layer around the algal cells and filaments. This enables an increase in nutrient uptake from the water column, resulting in enhanced periphyton photosynthesis, respiration, and specific growth rates (Biggs 1996). Conversely, increased velocity also increases the drag force on cells and filaments resulting in enhanced periphyton detachment through erosion and sloughing mechanisms.

Assemblage growth form strongly affects the degree to which mass transfer and drag change with hydrodynamic conditions. Likewise, the hydrodynamic environment will influence the prevalent periphyton growth form. Many researchers have described the effects of hydrodynamics on periphyton community assemblages and their architecture; primarily by describing the influence of mean flow field velocity. For example, Stevenson
(1984) found different algal assemblages depending on location on the substratum. Biggs et al. (1998) attributed the spatial distribution of periphyton in rivers to hydrodynamic heterogeneity and also to the interaction between growth form and velocity. Also, Nikora et al. (1997) used an ADV to elucidate some of the complex relationships between flow characteristics (buoyancy and drag) and periphyton architecture.

Hydrodynamics have also been shown to affect periphyton metabolism as first demonstrated by Whitford and Schumacher (1961) and Schumacher and Whitford (1965). They showed that, depending on algal species, a current velocity of $0.18 \mathrm{~m} / \mathrm{s}$ increased nutrient uptake dramatically over that occurring in still water. Others confirmed the phenomenon for uptake of carbon (Rodgers and Harvey 1976; Dodds 1989), nitrogen (Parker 1981), and phosphorus (Sperling and Grunewald 1969). The hydrodynamic flow field may also influence periphyton photosynthesis and oxygen dynamics. Previous research indicates that metabolic rates increase directly with water velocity, although maximum rates are not necessarily achieved at the highest velocity.

Recently, researchers have focused on improving the ability of environmental models to predict periphyton assemblages and their affect on water quality parameters. Bott and Newbold (2000) proposed the use of biofilm theory to describe interactions among

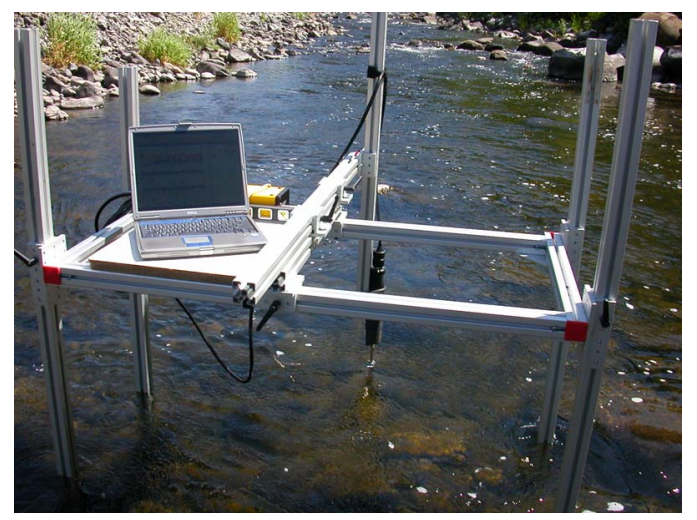

Fig. 1. ADV, sampling stand, and laptop computer in Potlatch River 


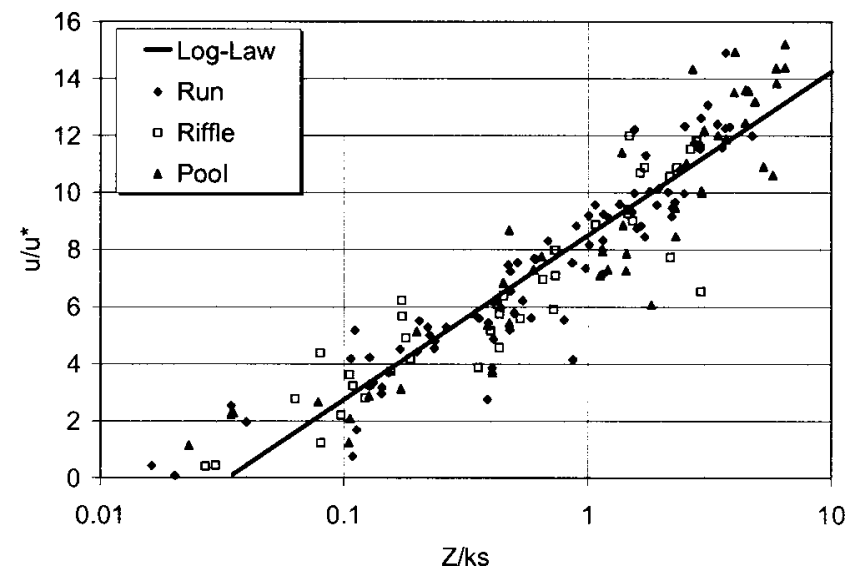

Fig. 2. Normalized velocity magnitude profiles segregated by habitat unit

flow velocity, nutrient uptake, and periphyton growth form. The researchers successfully applied the model to periphyton assemblages growing in controlled growth chambers. Larned et al. (2004) presented a conceptual model of mass-transfer limited periphyton growth. Like the Bott and Newbold approach, this model was closely related to a biofilm model, however it incorporated community architecture through a force balance approach on individual algae elements. Asaeda and Son (2000) presented a model of spatial structure and populations of a periphyton community. The model predicted periphyton growth as a Monod function and sloughing as a function of shear stress beyond a critical threshold. Application of such models to natural streams requires advanced information regarding flow field hydrodynamics, particularly near the streambed. However, such information is rarely available. This paper demonstrates techniques for collecting advanced flow metrics in natural streams at multiple spatial scales.

\section{Methods}

\section{Site Characterization}

Measurements were conducted in a $70 \mathrm{~m}$ reach of the St. Maries River near Clarkia, Idaho and a $60 \mathrm{~m}$ reach of the Potlatch River near Kendrick, Idaho. Stream geometry data were collected with a total station using standard surveying techniques (including stream banks, water surface and bed slopes, and cross-section geometries). Survey data were used to calculate mean depth $(H)$, hydraulic radius $\left(R_{H}\right)$, top width $\left(T_{w}\right)$, Reynolds number $(\mathrm{R})$, Froude number $(\mathrm{F})$, and global shear stress $\left(\tau_{g}\right)$.

The sediment particle size distributions (PSDs) were described using a Wolman pebble count (Wolman 1954). Approximately 100 samples were collected in the vicinity of each sampling station. Median particle diameters were 10.5 and $10.8 \mathrm{~cm}$ for the St. Maries and Potlatch Rivers, respectively. Both reaches were classified as cobble bed (Bunte and Abt 2001). The critical shear stress values, $\tau_{c}$, were estimated for the $d_{50}$ using the Shields parameter. Global shear stress estimates were far below critical values.

Data were collected at four cross sections in the St. Maries River and three cross sections in the Potlatch River. St. Maries cross sections 1, 2, 3, and 4 were classified as run, run, riffle, and pool, respectively. Potlatch cross sections 1, 2, and 3 were classified as riffle, run, and pool, respectively. These subjective classifications were based on observed flow velocities and depths. The classifications were specific to the observed conditions and likely would change at higher flows. For example, the entire Potlatch sampling reach would likely behave as a run under high flow conditions. Table 1 contains the geometric and hydraulic data for the sampled cross sections.

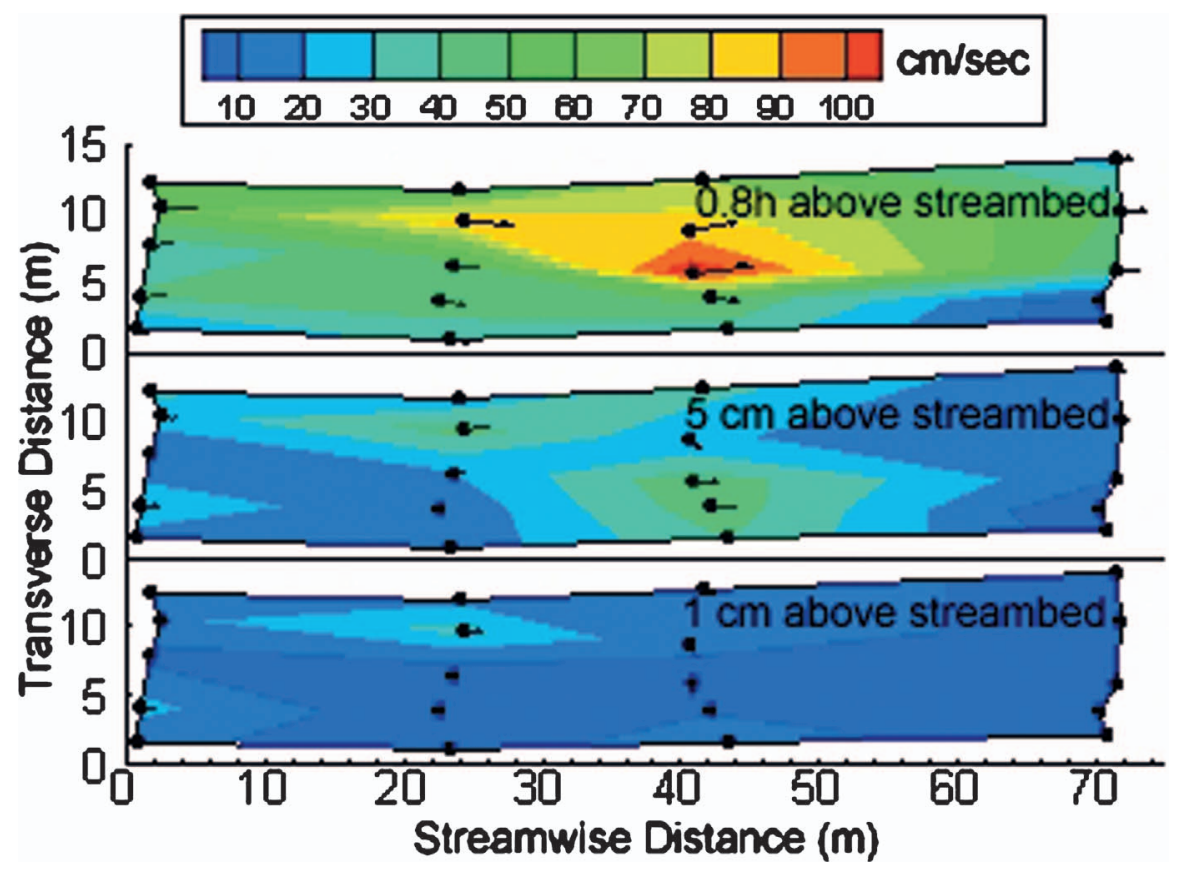

Fig. 3. (Color) Reach-scale velocity magnitude at $1 \mathrm{~cm}, 5 \mathrm{~cm}$, and $0.8 \mathrm{~h}$ above streambed 


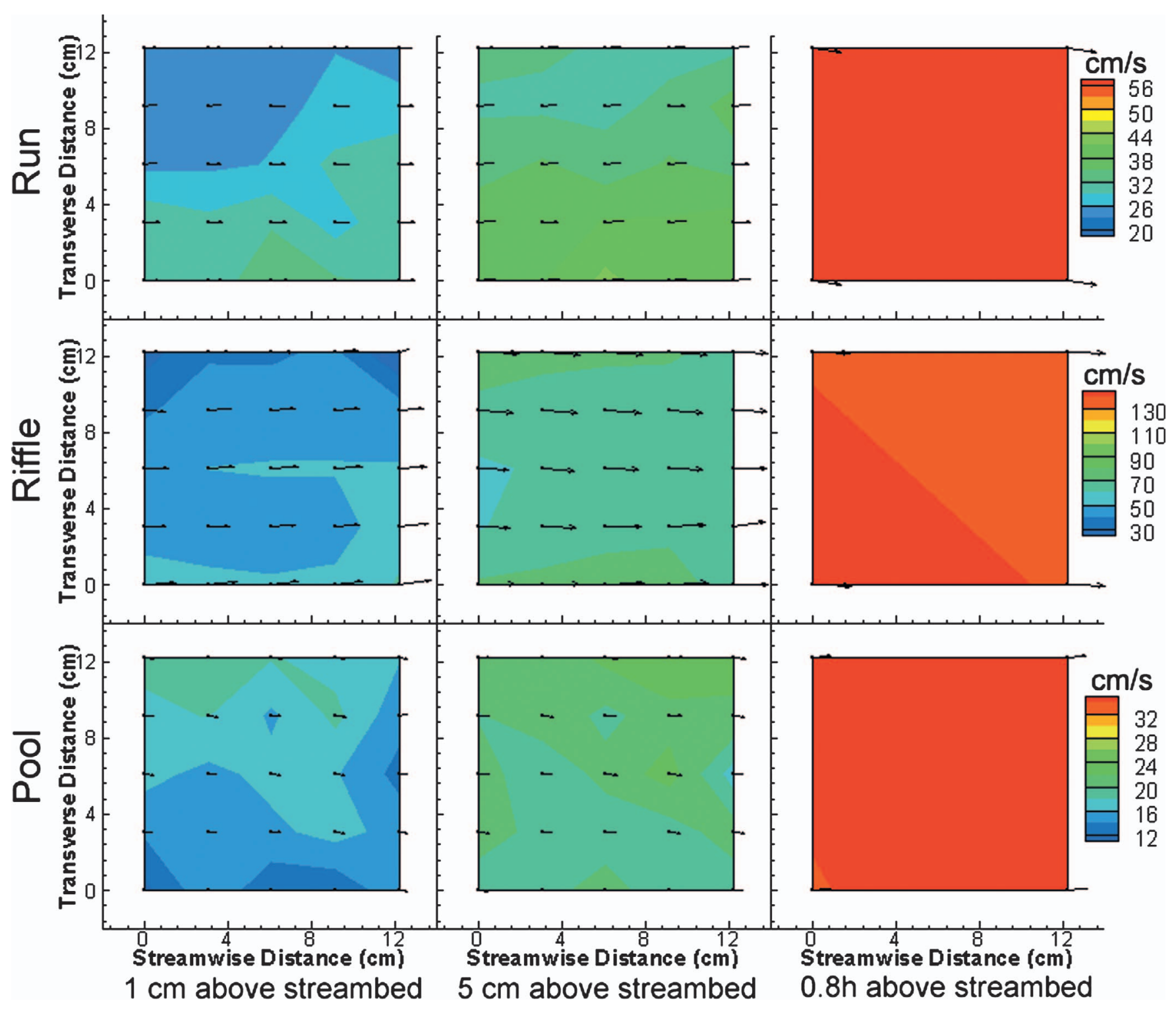

Fig. 4. (Color) High-resolution velocity magnitude at $1 \mathrm{~cm}, 5 \mathrm{~cm}$, and $0.8 \mathrm{~h}$ above streambed

\section{Flow Measurements}

The flow fields where measured with a $16 \mathrm{MHz}$ Micro ADV, manufactured by Sontek/YSI. The ADV operates on a pulse-topulse coherent Doppler shift. An acoustic signal is emitted by a transducer towards a sampling volume located approximately $5 \mathrm{~cm}$ away. The signal is reflected by ambient particles in the flow field and measured by three receivers separated by $120^{\circ}$ and approximately $7 \mathrm{~cm}$. The Doppler shift frequency along each receiver is used to calculate the three-dimensional water velocity. A detailed description of ADV operation principles can be found in Voulgaris and Trowbridge (1998). The ADV was mounted on a custom built sampling stand that was $1 \mathrm{~m}$ wide and $0.5 \mathrm{~m}$ long and fitted with four adjustable legs and an adjustable sampling arm (Fig. 1). The sampling arm extended a maximum of $0.5 \mathrm{~m}$ from the stand's front to avoid flow field interference, while cross-bracing prevented flow induced stand vibrations. The ADV processing canister and laptop computer were set on top of the stand. The ADV position was measured with a combination of vernier scales. The ADV measurements were conducted within two days of the initial site survey. Stream discharge was measured during the site characterization and before and after each day of sampling. All sampling was completed within three days at each reach, in which stream discharge did not change by more than $8 \%$ between all measurements.

Samples were collected at three to five stations within each cross section (henceforth referred to as "course-scale"). A vertical profile was measured at each station at heights above the streambed of 1, 2, and $5 \mathrm{~cm}$ along with 20, 40, 60, and $80 \%$ of the flow depth. The distance between the sampling volume and the bed was determined using the ADV as a sounder for the first three measurements. The vernier scales were used to position the instrument for the top four measurements. Data were collected for 2 min at each location at a sampling frequency of $25 \mathrm{~Hz}$. The suitability of the 2-min sample duration was validated by collecting 8-min samples at several stations and observing the convergence of mean velocity and standard deviation. At all tested locations, the divergence between the 8-min sample and the moving averages was less than $1 \%$ at $40 \mathrm{~s}$ or less for both mean velocity and velocity standard deviation.

ADV measurements were also conducted at a higher spatial 

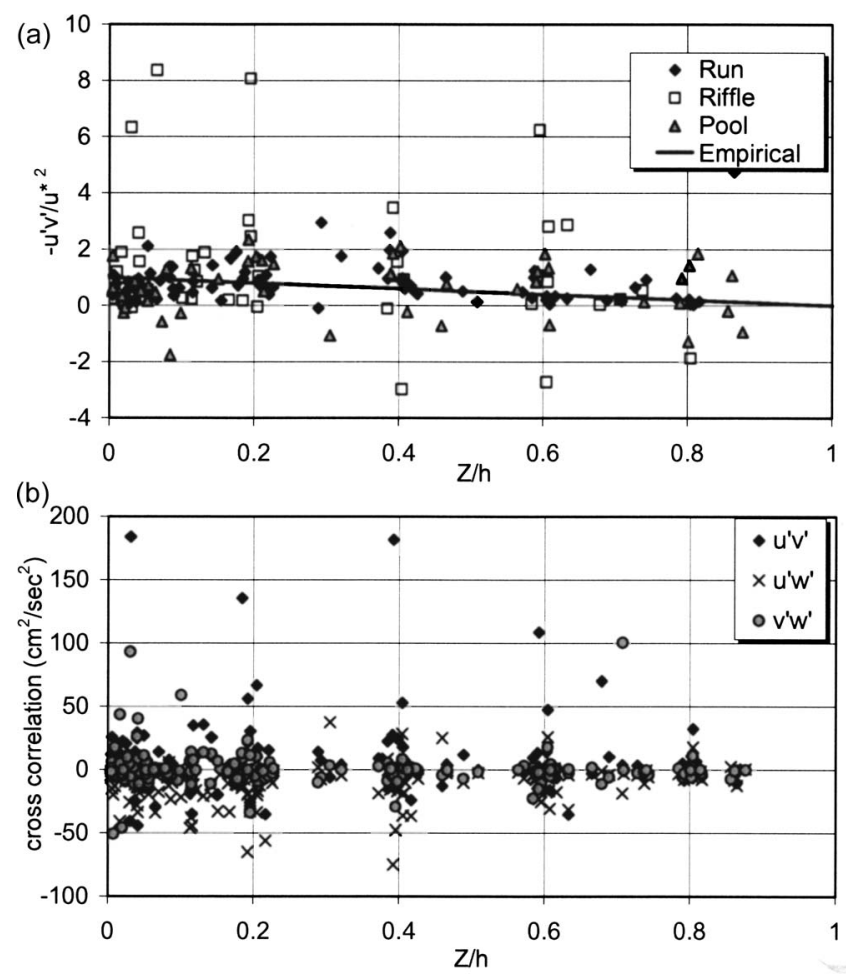

Fig. 5. (a) Vertical profile of normalized streamwise-vertical cross correlation coefficients; (b) all cross-correlation coefficients

resolution (henceforth referred to as "fine scale") at the central station of each cross section in the St. Maries River. Data were collected in a five-by-five point grid with a $3 \mathrm{~cm}$ spatial resolution within horizontal planes located 1 and $5 \mathrm{~cm}$ above the streambed, and in a two-by-two point grid with a $12 \mathrm{~cm}$ resolution at a relative depth of $0.8 \mathrm{~h}$. Data were also collected in a vertical profile in the center of the grid in order to calculate local bedshear stress.
The streamwise coordinate system was used in the data analysis. This was accomplished by decomposing the velocity into streamwise $(u)$, transverse $(v)$, and vertical $(w)$ components (Wilczak et al. 2001). Although every attempt was made during data collection to orient the instrument to the direction of flow, a slight misalignment was unavoidable. The tilt correction algorithms, proposed by Wilczak, were used to realign the data to the actual streamline coordinate system. This was achieved by setting the mean transverse, vertical, and cross-correlation (transverse multiplied by vertical) velocities equal to zero for each station. The variation between the measured and streamwise coordinate systems was less than $5^{\circ}$ for all stations.

The data were filtered at a minimum signal to noise ratio of 15 and a minimum correlation value of 70 using WINADV (Wahl 2000). Spectral densities were also reviewed for anomalies from expected distributions. This process eliminated about $5 \%$ of the data. The data were exported and processed using a custom developed FORTRAN code (Stone 2005). The FORTRAN program converted the data to the streamwise coordinate system and computed the flow field parameters including mean velocities, TI, TKE, and cross-correlations coefficients.

\section{Results}

Here we present the results of the ADV measurements of velocity, cross-correlation coefficients, turbulence intensity, and turbulent kinetic energy collected at two spatial scales in two cobble bed rivers. Vertical profiles of the measured data were evaluated at the reach scale and compared with the semiempirical equations described above. Horizontal heterogeneity of the flow variables was described at both the reach and fine scales.

\section{Velocity}

Observations of velocity magnitude were normalized with the friction velocity and plotted against the log-law with the von

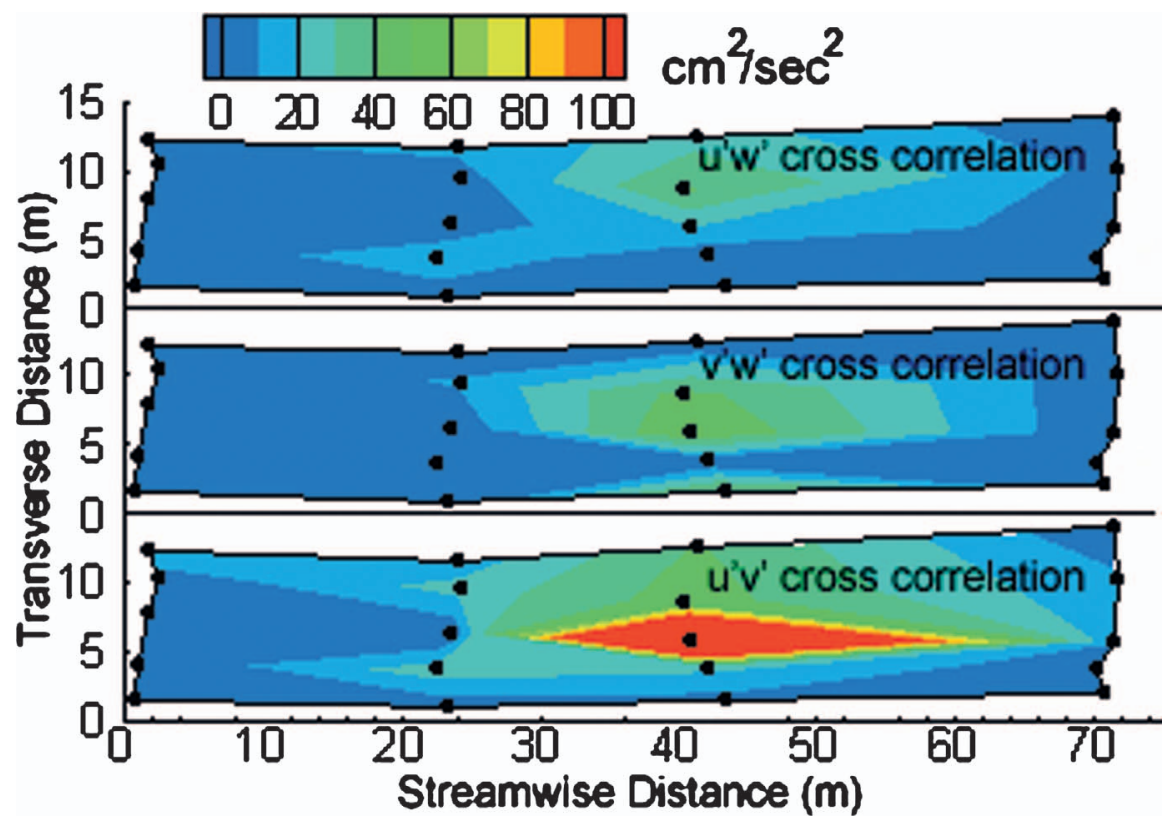

Fig. 6. (Color) Reach-scale cross-correlation coefficients $1 \mathrm{~cm}$ above streambed for St. Maries River 


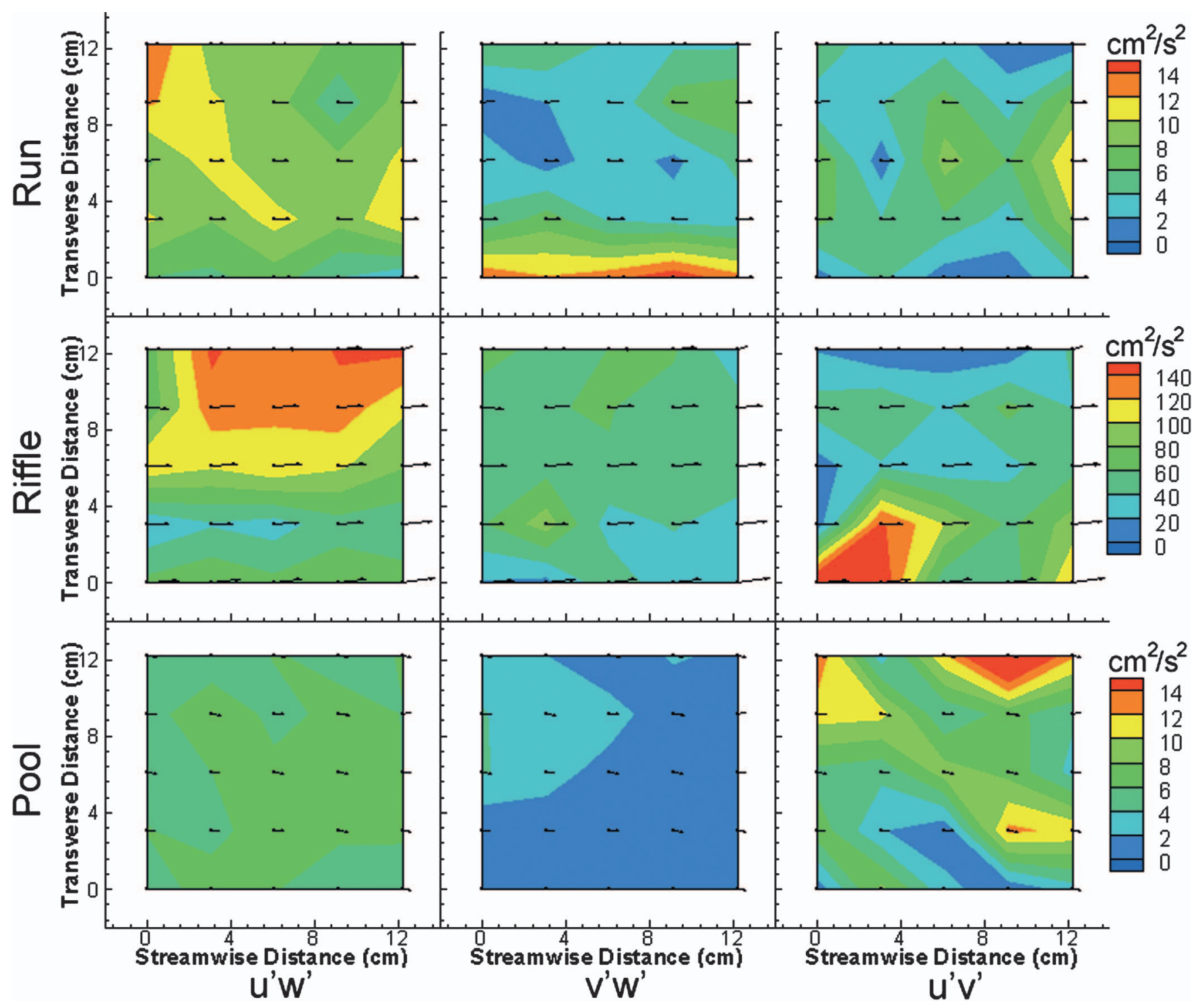

Fig. 7. (Color) High-resolution cross-correlation coefficients for each habitat unit $1 \mathrm{~cm}$ above streambed

Kármán constant taken as $0.41, k_{s}$ as the median local particle size, and $B$ and $\Delta z$ determined with the least-squares fitting method. The experimental points collapsed around the log-law for each stream unit as shown in Fig. 2. Although some scatter around the log-law profile was observed, the measured data followed the log-law relatively well. As expected, the greatest deviations were observed near the streambed and near the water surface. Regression analyses were performed for each habitat unit and for the dataset as a whole. The results confirmed the predictive ability of the logarithmic profile as $R^{2}$ values for the riffle, run, pool, and composite datasets were $0.67,0.87,0.85$, and 0.78 , respectively, with nearly perfect agreement with the log-law function. Deviations of velocity measurements from the log-law were likely due to large streambed particles, secondary flows, and irregular banks.

Two-dimensional contour plots of velocity magnitude in the St. Maries River are shown for the reach- and fine-scale measurements in Figs. 3 and 4, respectively. Both figures represent horizontal "slices" of velocity data measured at $1 \mathrm{~cm}, 5 \mathrm{~cm}$, and $0.8 \mathrm{~h}$ above the streambed. As expected, the data reveal that the highest velocity magnitudes were observed in the riffle and the lowest in the pool, with velocity increasing with distance from the streambed. Velocity magnitude in the riffle was an order of magnitude higher in the riffle, at over $100 \mathrm{~cm} / \mathrm{s}$, than in the pool, at approximately $10 \mathrm{~cm} / \mathrm{s}$. Also, the observed velocities were generally higher towards the center of the stream. Fig. 4 contains fine-scale velocity distributions segregated by habitat unit. In order to accentuate the spatial heterogeneity within each habitat unit, different velocity contour intervals were used for the riffle, run, and pool plots. Spatial heterogeneity was highest near the streambed where the velocity magnitude varied by more than $10 \mathrm{~cm} / \mathrm{s}$ for all habitat units. Heterogeneity was highest in the riffle where velocity magnitude near the bed $(1 \mathrm{~cm})$ ranged from 18.7 to $59.9 \mathrm{~cm} / \mathrm{s}$. This was likely caused by the larger sediment particles in the riffle compared to the run and pool. These results are ecologically important because organisms present in high velocity regions of a stream require refugia to avoid constant exposure to elevated velocity.

\section{Reynolds Shear Stress}

Profiles of cross-correlation coefficients are shown in Fig. 5. Fig. 5(a) contains the normalized $u^{\prime} w^{\prime}$ (streamwise-vertical) profiles 

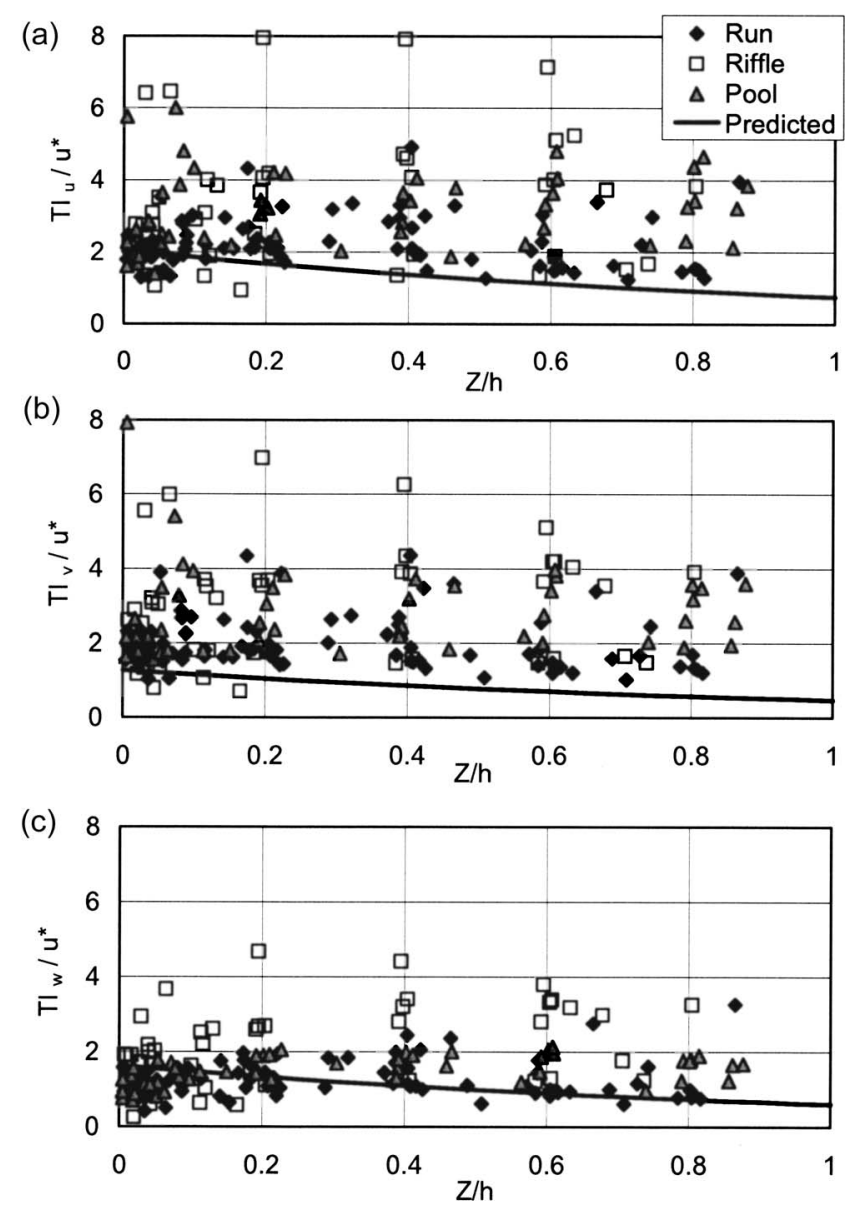

Fig. 8. Normalized: (a) streamwise; (b) transverse; and (c) vertical turbulence intensities

for each habitat unit along with the expected linear vertical profile from Eq. (6). The $u^{\prime} w^{\prime}$ values were similar between stream units except for relatively high scatter for the riffle habitat unit. Although most $u^{\prime} w^{\prime}$ profiles generally decreased in magnitude from the bed towards the water surface, the effect was much weaker than expected. As with velocity, the departure of the observed data from the expected trends can likely be attributed to deviations from uniform flow, large bed particles, and secondary currents. The maximum $\tau_{R}$ values were generally observed away

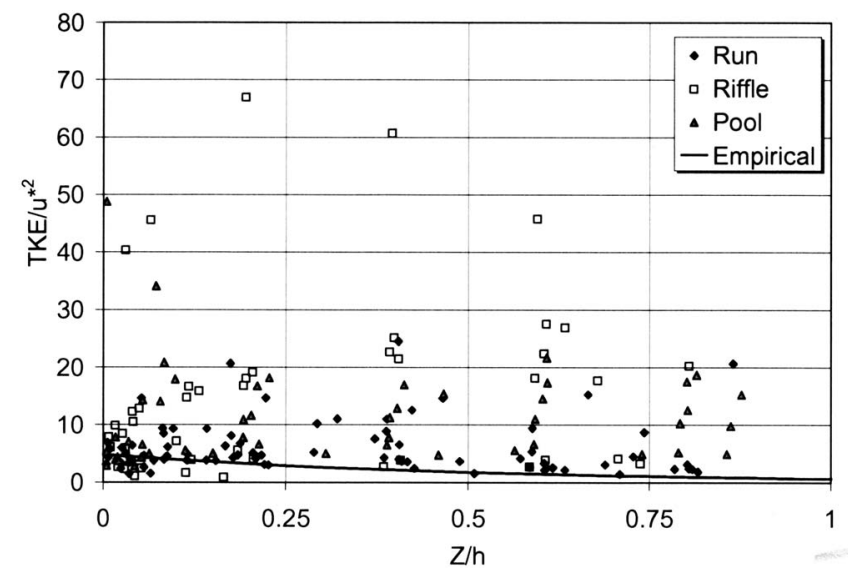

Fig. 9. Normalized TKE profiles segregated by habitat unit from the streambed, indicating the emergence of additional mechanisms for momentum extraction from the flow field (Nikora and Goring 2000). Papanicolaou and Hilldale (2002) provided a detailed description of the nonlinear influence of secondary currents on Reynolds shear stress profiles. Chen and Chiew (2003) also observed a modified $\tau_{R}$ profile caused by the formation of an internal boundary layer as a result of a change in bed roughness.

Vertical profiles for all cross-correlation coefficients $\left(u^{\prime} w^{\prime}\right.$, $v^{\prime} w^{\prime}$, and $\left.u^{\prime} v^{\prime}\right)$ are shown in Fig. 9(b). A notable result is the similar magnitude observed for all coefficients. As described above, in two-dimensional open channel flow the streamwisevertical cross-correlation coefficient $\left(u^{\prime} w^{\prime}\right)$ is typically dominant and therefore the other coefficients are often neglected. The high values for $u^{\prime} v^{\prime}$ and $v^{\prime} w^{\prime}$ suggest that all cross-correlation coefficients must be considered when investigating Reynolds shear stress distributions in similar environments.

Cross-correlation coefficients $1 \mathrm{~cm}$ above the streambed at the reach and fine scales are plotted in Figs. 6 and 7, respectively. High spatial heterogeneity was observed for all coefficients and habitat units as $u^{\prime} v^{\prime}$ ranged from approximately $1 \mathrm{~cm}^{2} / \mathrm{s}^{2}$ in the pool to more than $200 \mathrm{~cm}^{2} / \mathrm{s}^{2}$ in the riffle. Both $u^{\prime} w^{\prime}$ and $v^{\prime} w^{\prime}$ showed less variation, ranging from about 1 to $50 \mathrm{~cm}^{2} / \mathrm{s}^{2}$. All coefficients were of similar magnitude in the riffle and pool habitat units, but $u^{\prime} v^{\prime}$ values were much higher in the riffle. A closer evaluation revealed strong transverse velocity fluctuations near the streambed in that region. As with velocity, different contour intervals were required in order to illustrate spatial heterogeneity within each habitat unit at the fine scale. Patterns and values were similar between habitat units and coefficients. Once again the highest variability was observed in the riffle for all three crosscorrelation coefficients. As with the reach scale, the streamwisetransverse coefficient $\left(u^{\prime} v^{\prime}\right)$ showed the greatest variability ranging from 4 to $170 \mathrm{~cm}^{2} / \mathrm{s}^{2}$.

\section{Turbulence Intensity and Turbulent Kinetic Energy}

Normalized streamwise $\left(\mathrm{TI}_{u}\right)$, transverse $\left(\mathrm{TI}_{v}\right)$, and vertical $\left(\mathrm{TI}_{w}\right)$ turbulence intensity and TKE profiles are shown in Figs. 8 and 9, respectively. TI and TKE values were generally highest in riffles and lowest in the pools. Another notable observation was that $\mathrm{TI}_{v}$ values were of approximately the same magnitude as $\mathrm{TI}_{u}$ values. The semiempirical Eqs. $(7 a)-(7 d)$ are displayed in Figs. 8 and 9 using the coefficients suggested by Nezu and Nakagawa (1993). The observed data deviated considerably from the predicted values in terms of both magnitude and pattern. The overall magnitude of the TI and TKE observations were much higher than those estimated by the semiempirical equations. This was likely caused by additional turbulence production mechanisms, including the presence of large roughness elements, irregular banks, and secondary currents. In contrast, Eqs. $(7 a)-(7 d)$ are based on a model of bed-produced turbulence in an equilibrium condition, where production and dissipation of TKE are balanced. Regardless of the values of the empirical constants, Eqs. $(7 a)-(7 d)$ predict a peak in TI and TKE near the streambed and decreasing values away from the bed due to their negative exponent. For the observed data, the peak TI and TKE values generally occurred at a considerable distance from the bed. As suggested by Wang et al. (1993) and Carollo et al. (2005) the increased distance of the peak values of TI and TKE from the bed is likely caused by the presence of large roughness elements. Also, the reduction in TI and TKE values with distance from the bed was weaker than expected. This was likely due to channel nonuniformity. Papanico- 


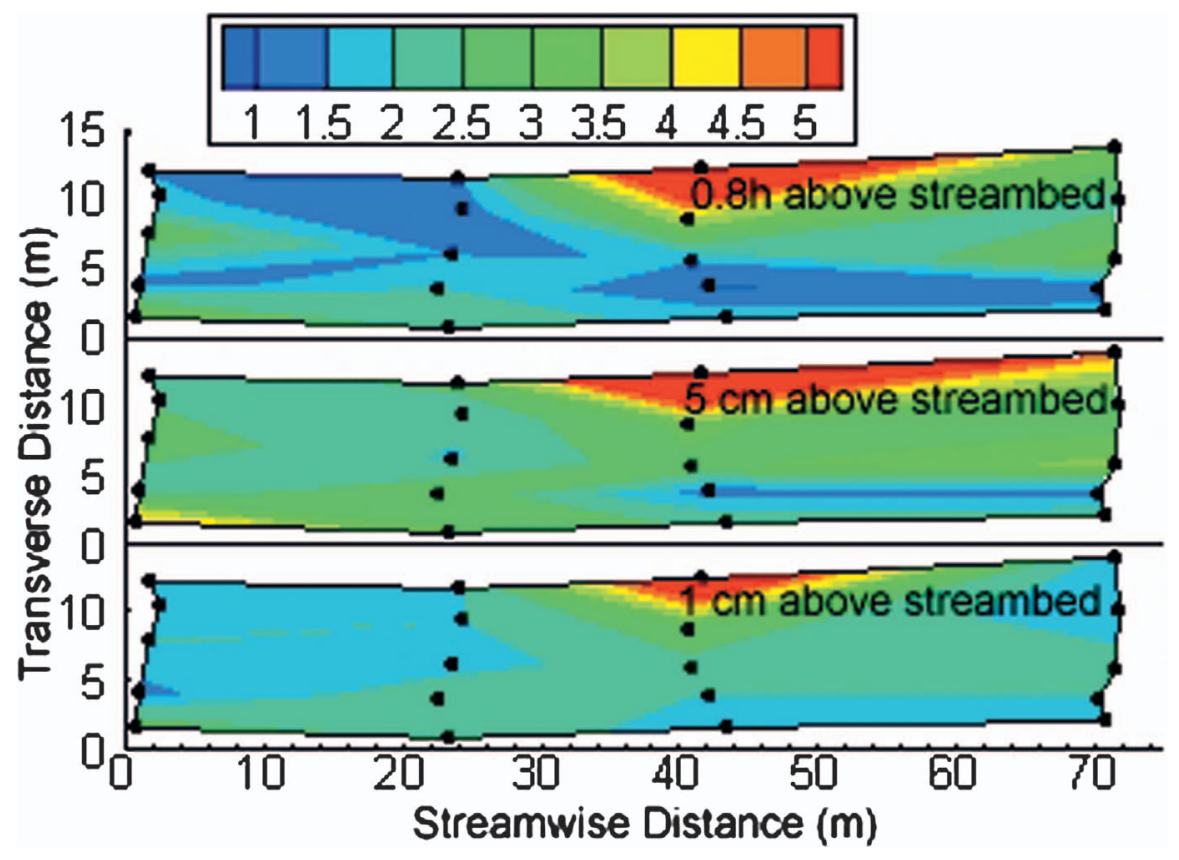

Fig. 10. (Color) Reach-scale normalized turbulence intensity magnitude at $1 \mathrm{~cm}, 5 \mathrm{~cm}$, and $0.8 \mathrm{~h}$ above streambed

laou and Hilldale (2002) and Song and Chiew (2001) observed a strong influence of channel transitions on vertical profiles of TI and TKE. The authors attributed this to momentum transfer from the bed to the free surface due to secondary currents, rather than from the core of the flow to the bed. Finally, $\mathrm{TI}_{v}$ values were slightly higher than $\mathrm{TI}_{w}$ values, which contradict previous experiments. $\mathrm{TI}_{v}$ observations were likely elevated by the presence of secondary currents.

Contour plots of normalized turbulence intensity observations at the reach and fine scales are shown in Figs. 10 and 11, respectively. High spatial heterogeneity was observed within the reach scale with the highest TI observed in the riffle with lower values observed in the run and pool. High TI values were observed on the left side of the riffle, corresponding to a large velocity gradient, large sediment particles, and an irregular bank. Similar TI magnitudes were observed at all depths. As with the fine-scale plots of velocity and cross-correlation coefficients, it was necessary to use different contour intervals for each habitat unit in order to accentuate spatial heterogeneity in TI observations. Again, high spatial variability was observed near the streambed with more homogeneous values near the water surface. The highest overall values and also the widest variability were observed in the riffle where normalized TI ranged from approximately 3.1 to 5.3 near the streambed and from 3.1 to 3.3 at $0.8 \mathrm{~h}$. Overall, greater spatial variability was observed for both velocity magnitude and cross-correlation coefficients.

\section{Discussion}

The objective of this research was to demonstrate how turbulent flow field data contribute to an ecohydraulics study. This was accomplished by conducting ADV measurements in two cobblebed rivers at two spatial scales. The results can be used to improve understanding of the influence of hydrodynamic flow properties on periphyton heterogeneity and relevant ecological processes. Further, the techniques demonstrated here can be used to investigate detailed hydrodynamic properties within similar flow environments. The results also provide insight regarding points of emphasis and potential pitfalls in developing measuring strategies.

The study results revealed that the traditional logarithmic profile predicted velocity fairly well when compared to the measured data. As expected, higher variability in velocity distributions was observed near the streambed, due to the influence of local bed features, and near the water surface. The velocity varied by a full order of magnitude within the St. Maries River. At the fine scale, high spatial heterogeneity was found within relatively small regions (varying by as much as $200 \%$ within $144 \mathrm{~cm}^{2}$ ), particularly in the high-velocity riffle. This observation has important implications for benthic organisms, such as periphyton, which rely on refugia in regions of high velocity.

Investigations of Reynolds shear stress distributions revealed that all cross-correlation coefficients $\left(u^{\prime} w^{\prime}, u^{\prime} v^{\prime}\right.$, and $\left.v^{\prime} w^{\prime}\right)$ contributed strongly to the overall $\tau_{r}$. Unlike typical two-dimensional flows, $u^{\prime} v^{\prime}$ in some instances was equal to, or greater than, $u^{\prime} w^{\prime}$. Also, spatial heterogeneity of cross-correlation coefficients was quite high, varying by two orders of magnitude at the reach scale and by more than one order of magnitude at the fine scale. The results are noteworthy considering the importance of $\tau_{r}$ estimates in predicting periphyton sloughing and other ecological and physical processes near the streambed. The results suggest that reach scale estimates of $\tau_{r}$ are inadequate for predicting periphyton heterogeneity. Field measurements and environmental models that are intended to describe or predict periphyton architecture, biomass, and metabolism should be designed with this in mind. Further, the results indicate that it is important to consider all cross-correlation coefficients when investigating the influence of Reynolds shear stresses on stream processes. For example, threedimensional velocity measurements may be required in order to properly investigate the influence of $\tau_{R}$ on periphyton sloughing. Finally, the spatial variability illustrates the necessity of conducting hydrodynamic measurements at scales commensurate with the 


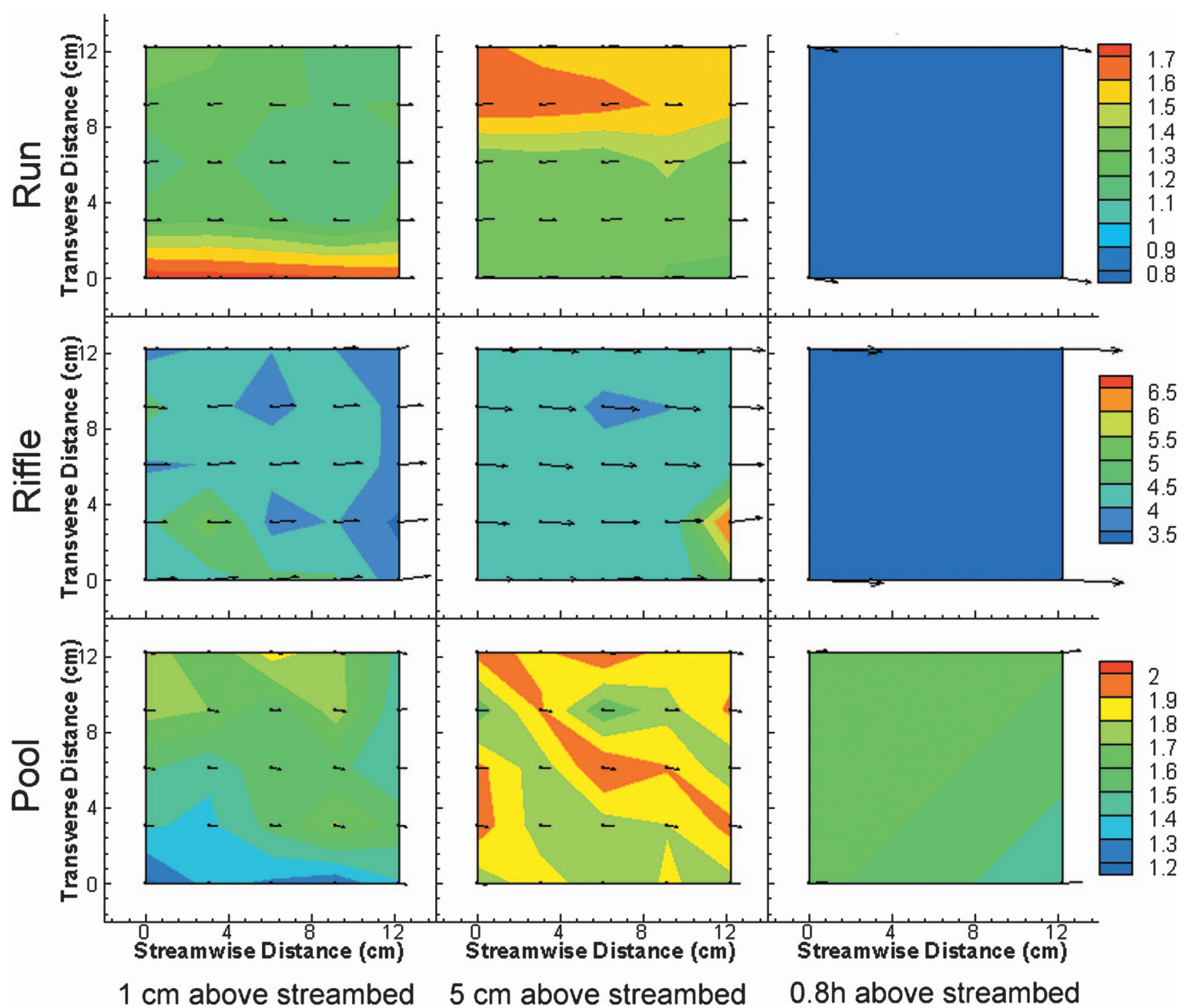

Fig. 11. (Color) Normalized turbulence intensity magnitudes for each habitat unit at $1 \mathrm{~cm}, 5 \mathrm{~cm}$, and $0.8 \mathrm{~h}$ above streambed

processes of interest. For example, the spatially averaged $u^{\prime} w^{\prime}$ magnitude for the riffle habitat unit was $89 \mathrm{~cm}^{2} / \mathrm{s}^{2}$. However, the local periphyton assemblage was actually exposed to a range of values between 20 and $145 \mathrm{~cm}^{2} / \mathrm{s}^{2}$.

Spatial heterogeneity for TI and TKE was less apparent than for velocity and the cross-correlation coefficients. The semiempirical TI and TKE equations inadequately described the turbulence distributions. Overall, the magnitudes of these parameters were much higher than expected. The maximum TI and TKE values occurred farther from the bed than predicted and the values did not decline towards the water surface as expected. This was likely caused by high relative roughness and irregular stream banks. The results are ecologically important because elevated TI and TKE levels are believed to reduce the thicknesses of the diffusive boundary layer and therefore increase mass transfer of nutrients to the periphyton mat.

There were several limitations to the present study that will be addressed through future research. First, a standardized uncertainty analysis for ADV-based measurements has not been performed. Such an analysis would require estimates of both systematic and precision uncertainty and the propagation of such uncertainty through the calculation of turbulence parameters (González-Castro and Chen 2005). Given the complexity of such an analysis and the high level of variability associated with the biological parameters of interest, the uncertainty analysis has been left for future research. An additional limitation in this study was the number of datapoints that could be collected within a reasonable timeframe. Future research would benefit from using multiple ADVs or by combining ADV measurements with other velocity measurement techniques (i.e., acoustic Doppler current profiler).

The research results have implications beyond the current study. The data presented in this paper are specific to the measured stream reaches and flow conditions. However, the data patterns described here are likely representative of distributions of hydrodynamic properties in similar environments. Further, the field measurement techniques demonstrated here are widely applicable to ecosystem studies in wadeable streams that require detailed descriptions of flow properties. Thus, this study will assist engineers and scientists in designing and implementing future ecohydraulic investigations. 


\section{Acknowledgments}

This research was supported by a grant from the State of Washington Water Research Center. The writers would like to acknowledge the contributions of Ryan Morrison, Alden Chato, and Asako Stone in assisting with field measurements. Also, the advice provided by three anonymous reviewers was invaluable in improving the quality of this manuscript.

\section{Notation}

The following symbols are used in this paper:

$a, b, c, d$, and $C_{k}=$ empirical constants for TI and TKE profiles;

$B=$ log-law integration constant;

$d_{50}=$ median particle size diameter;

$E=$ error between ADCP, Price, and ADV velocity measurements;

$\mathrm{F}=$ Froude number;

$H=$ mean water depth;

$h=$ local water depth;

$k_{s}=$ roughness height;

$Q=$ discharge;

$\mathrm{R}=$ Reynolds number;

$R_{H}=$ hydraulic radius;

$S=$ water surface slope;

$S_{b}=$ bed slope;

$T_{w}=$ top stream width;

$\mathrm{TI}=$ turbulence intensity;

$\mathrm{TKE}=$ turbulent kinetic energy;

$U=$ mean velocity;

$u=$ instantaneous velocity components;

$\bar{u}=$ time-averaged velocity components;

$u^{\prime}=$ fluctuating velocity components;

$u_{*}=$ friction velocity;

$z=$ distance from streambed;

$\Delta z=$ displacement length;

$\gamma=$ fluid specific weight;

$\kappa=$ von Kármán constant;

$\mu=$ dynamic viscosity;

$\rho=$ fluid density;

$\tau=$ shear stress;

$\tau_{c}=$ critical shear stress;

$\tau_{g}=$ global shear stress;

$\tau_{\mathrm{R}}=$ Reynolds shear stress; and

$\tau_{0}=$ bed-shear stress.

\section{References}

Asaeda, T., and Son, D. H. (2000). "Spatial structure and populations of a periphyton community: A model and verification." Ecol. Modell., 133(3), 195-207.

Biggs, B. J. F. (1996). "Patterns in benthic algae of streams." Algal ecology: Freshwater benthic ecosystems, R. J. Stevenson, M. L. Bothwell, and R. L. Lowe, eds., Academic, San Diego.

Biggs, B. J. F., Goring, D. G., and Nikora, V. I. (1998). "Subsidy and stress responses of stream periphyton to gradients in water velocity as a function of community growth form." J. Phycol., 34, 598-607.

Bott, T., and Newbold, J. (2000). "Effects of water velocity on Jackson River periphyton. Biomass and nutrient uptake." Publication No. 2000005, Stroud Water Center, Avondale, Pa.
Buffin-Belanger, T., Roy, A. G., and Kirkbride, A. D. (2000). "On largescale flow structures in a gravel-bed river." Geomorphology, 32(3-4), 417-435.

Bunte, K., and Abt, S. R. (2001). "Sampling surface and subsurface particle-size distributions in wadable gravel- and cobble-bed streams for analyses in sediment transport, hydraulics, and streambed monitoring.” U.S. Dept. of Agriculture, Forest Service, Rocky Mountain Research Station, Fort Collins, Colo.

Carollo, F. G., Ferro, V., and Termini, D. (2005). "Analyzing turbulence intensity in gravel bed channels." J. Hydraul. Eng., 131(12), 10501061.

Chen, X., and Chiew, Y. M. (2003). "Response of velocity and turbulence to sudden change of bed roughness in open-channel flow." J. Hydraul. Eng., 129(1), 35-43.

Dodds, W. K. (1989). "Photosynthesis of two morphologies of Nostoc parmelioides (Cyanobacteria) as related to current velocities." J. Phycol., 25, 258-262.

González-Castro, J. A., and Chen, Z. (2005). "Uncertainty of indexvelocity measurement at culverts." Proc., World Water and Environmental Resources Congress, Anchorage, Alaska.

Hart, D. D., and Finelli, C. M. (1999). "Physical-biological coupling in streams: The pervasive effects of flow on benthic organisms." Annu. Rev. Ecol. Syst., 30, 363-395.

Kironoto, B. A., and Graf, W. H. (1994). "Turbulence characteristics in rough uniform open-channel flow." Proc. Inst. Civ. Eng., Waters. Maritime Energ., 106, 333-344.

Larned, S. T., Nikora, V. I., and Biggs, B. J. F. (2004). "Mass-transferlimited nitrogen and phosphorus uptake by stream periphyton: A conceptual model and experimental evidence." Limnol. Oceanogr., 49, 1992-2000.

Nezu, I. (2005). "Open-channel flow turbulence and its research prospects in the 21st Century." J. Hydraul. Eng., 131(4), 229-246.

Nezu, I., and Nakagawa, H. (1993). Turbulence in open-channel flows, Balkema, Rotterdam, The Netherlands.

Nikora, V. I., and Goring, D. (2000). "Flow turbulence over fixed and weakly mobile gravel beds." J. Hydraul. Eng., 126(9), 679-690.

Nikora, V. I., Goring, D. G., and Biggs, B. J. F. (1997). "On stream periphyton-turbulence interactions." ASEE Prism, 31, 435-448.

Nikora, V. I., and Smart, G. M. (1997). "Turbulence characteristics of New Zealand gravel-bed rivers.” J. Hydraul. Eng., 123(9), 764-773.

Nikuradse, J. (1933). "Stromungsgesetze in rauhen Rohren." Heft 361, Berlin.

Papanicolaou, A. N., and Hilldale, R. (2002). "Turbulence characteristics in gradual channel transition.” J. Eng. Mech., 128(9), 948-960.

Parker, H. S. (1981). "Influence of relative water motion on the growth, ammonoium uptake, and carbon and nitrogen composition of Ulva lactuaca (Chlorophyta)." Mar. Biol. (Berlin), 63, 309-318.

Prandtl, L. (1932). "Zur turbulenten stromung in rohren und langs platten." Ergebnisse der Aerodynamischen Versuchsantalt zu Gottingen, 4, 18-29.

Rennie, C. D., Fisher, T. S. R., and Millar, R. G. (1999). "Spatial variability of turbulent velocity structure in a natural river." Proc., 1999 World Water and Environmental Resources Congress, Seattle.

Reynolds, A. J. (1974). Turbulent flows in engineering, Wiley, New York.

Rodgers, J. H., and Harvey, R. S. (1976). "The effect of current on periphytic productivity as determined using carbon-14." Water Resour. Bull., 12, 1109-1118.

Schumacher, G. J., and Whitford, L. A. (1965). "Respiration and P-32 uptake in various species of freshwater algae as affected by a current." J. Phycol., 1, 78-80.

Song, T., and Chiew, Y. M. (2001). "Turbulence measurement in nonuniform open-channel flow using acoustic Doppler velocimeter (ADV)." J. Eng. Mech., 127(3), 219-232.

Song, T., Lemmin, U., and Graf, W. H. (1994). "Uniform-flow in open channels with movable gravel-bed." J. Hydraul. Res., 32(6), 861876.

Sperling, J. A., and Grunewald, R. (1969). "Batch culturing of thermophilic benthic algae and phosphorus uptake in a laboratory stream 
model." Limnol. Oceanogr., 14, 944-949.

Stevenson, R. J. (1984). "How currents on differing sides of substrates in streams affect mechanisms of benthic algal accumulation." Internationale Revue der gesamten Hydrobiologie, 69, 241-262.

Stone, M. C. (2005). "Natural stream flow fields: measurements and implications for periphyton." Dissertation, Washington State Univ., Pullman, Wash.

Sukhodolov, A. N., Thiele, M., and Bungartz, H. (1998). "Turbulence structure in a river reach with sand bed." Water Resour. Res., 34(5), 1317-1334.

Tritico, H. M., and Hotchkiss, R. H. (2005). "Unobstructed and obstructed turbulent flow in gravel bed rivers." J. Hydraul. Eng., 131(8), 635-645.

von Kármán, T. (1930). "Mechanische ahnlichkeit und turbulenz." Gottinger Nachrichten, Math. Phys. Klasse, 58-60.

Voulgaris, G., and Trowbridge, J. H. (1998). "Evaluation of the acoustic Doppler velocimeter (ADV) for turbulence measurements." J. Atmos.
Ocean. Technol., 15, 272-289.

Wahl, T. L. (2000). Analyzing ADV data using WinADV, American Society of Civil Engineers, Minneapolis.

Wang, J., Dong, Z., Chen, C., and Xia, Z. (1993). "The effects of bed roughness on the distribution of turbulent intensities in open channel flow." J. Hydraul. Res., 31(1), 89-98.

Wetzel, R. G. (2001). "Periphyton in freshwater ecosystems." Limnol. Oceanogr., 30(4), 917-918.

Whitford, L. A., and Schumacher, G. J. (1961). "Effect of current on mineral uptake and respiration by a freshwater alga." Limnol. Oceanogr., 6, 423-425.

Wilczak, J. M., Oncley, S. P., and Stage, S. A. (2001). "Sonic anemometer tilt correction algorithms." Boundary-Layer Meteorol., 99, 127150

Wolman, M. G. (1954). "A method of sampling coarse bed material." Trans., Am. Geophys. Union, 35, 951-956. 
Copyright of Journal of Hydraulic Engineering is the property of American Society of Civil Engineers and its content may not be copied or emailed to multiple sites or posted to a listserv without the copyright holder's express written permission. However, users may print, download, or email articles for individual use. 